\title{
PENERAPAN METODE PEMBELAJARAN CARD SORT DALAM UPAYA PENINGKATAN HASIL BELAJAR POKOK BAHASAN SIKAP KEPAHLAWANAN DAN PATRIOTISM KELAS IV SDN PURWOSARI 02
}

\author{
Nurhidayati \\ Sekolah Dasar Negeri Purwosari 02 \\ sayanurhidayati123@gmail.com
}

\begin{abstract}
Social Studies (IPS) is one of the subjects taught in elementary school students so that they know the future of natural phenomena and social phenomena ranging from the environment close to the more distant environment (world). This research method is classroom action research (PTK) which implement the actions in the classroom by using rules in accordance with the methodology of the research conducted in several periods or cycles. The material is selected in the application of this classroom action research is a matter of heroism. This study shows the progress made in the form of learners' test results improved. Formative test results of students in the first cycle the number of students who reached the KKM many as eight students with a percentage of $23.5 \%$. In the second cycle students who reached the KKM number of 28 students with a percentage of $82.4 \%$. There is an increase in student formative test results that indicate that the application of the model card sort can increase the students' learning outcomes.
\end{abstract}

Key Words Card sort, the value of heroism, IPS Learning, Classroom Action Research.

\begin{abstract}
ABSTRAK
Ilmu Pengetahuan Sosial (IPS) merupakan salah satu mata pelajaran yang mengajarkan pada siswa SD agar mereka kelak mengenal fenomena alam dan fenomena sosial mulai dari lingkungan yang dekat sampai kepada lingkungan yang lebih jauh (dunia). Metode penelitian ini adalah penelitian tindakan kelas (PTK) yang menerapkan tindakan didalam kelas dengan menggunakan aturan sesuai dengan metodologi penelitian yang dilakukan dalam beberapa periode atau siklus. Materi yang dipilih dalam penerapan penelitian tindakan kelas ini adalah materi kepahlawanan. Penelitian ini memperlihatkan kemajuan yang dilakukan peserta didik dalam bentuk hasil tes yang meningkat. Hasil tes formatif siswa pada siklus I jumlah siswa yang mencapai KKM sebanyak 8 siswa dengan prosentase $23.5 \%$. Pada siklus II siswa yang mencapai nilai KKM sejumlah 28 siswa dengan prosentase $82.4 \%$. Terjadi kenaikan pada hasil tes formatif siswa sehingga menunjukkan bahwa penerapan model card sort dapat meningkatakan hasil belajar siswa.
\end{abstract}

Kata Kunci: Card sort, nilai kepahlawanan, Pembelajaran IPS, Penelitian Tindakan Kelas

\section{PENDAHULUAN}

Pasal 1 ayat 1 Undang-undang tentang sistem pendidikan nasional memberikan definisi pendidikan adalah usaha sadar dan terencana untuk mewujudkan suasana belahjar dan proses pembelajaran agar pesetrta didik secara aktif mengembangkan potensi dirinya untuk memiliki kekuatan spiritual keagamaan, pengendalian diri, kepribadian, kecerdasan, akhlak mulia, serta keterampilan yang diperlukan 
dirinya, masyarakat, bangsa dan Negara. Pendidikan merupakan dasar yang penting untuk mencetak sumber daya manusia yang berkualitas. Tanpa pendidikan suatu negara akan kesulitan untuk membangun bangsanya (Mulyasa, 2004). Maju mundurnya suatu bangsa banyak ditentukan oleh maju mundurnya suatu pendidikan di Negara tersebut. Kualitas pendidikan yang tinggi diperlukan untuk menciptakan kehidupan yang cerdas, damai, terbuka, demokratis dan mampu bersaing (Winaputra, 2010).

Di sisi lain, melalui pembelajaran IPS diharapkan mampu dikembangkan aspek pengetahuan dan pengertian (knowledge and understanding), aspek sikap dan nilai (atitude and value), dan aspek keterampilan (skill) (Skeel, 1995; Jarolimek, 1993). Untuk skala Indonesia, maka tujuan IPS khususnya pembelajaran IPS pada jenjang sekolah dasar sebagimana tecantum dalam Kurikulum IPS-SD Tahun 2006 adalah agar peserta didik mampu mengembangkan pengetahuan dan keterampilan dasar yang berguna bagi dirinya dalam kehidupannya sehari-hari (Depdiknas, 2006). Ilmu pengetahuan sosial juga membahas hubungan antara manusia dengan lingkungannya, yaitu lingkungan masyarakat dimana anak didik tumbuh dan berkembang sebagai bagian dari masyarakat, dan dihadapkan pada berbagai permasalahan yang ada dan Ilmu-ilmu social (social science) dapat diartikan sebagai bagian ilmu pengetahuan mengenai manusia dengan konteks sosialnya atau sebagai anggota masyarakat. Seperti yang dikemukakan oleh Mackenzie bahwa social sciences are all the academic disclipines which deal with men in their social context. Jadi jadi, dengan demikian tiap ilmu pengetahuan yang mempelajari dan mengkaji aspek kehidupan manusia dalam masyarakat, termasuk bagian ilmu-ilmu social.

Pengorganisasian materi mata pelajaran IPS menganut pendekatan terpadu (integrated), artinya mata 18 pelajaran dikembangkan dan disusun tidak mengacu pada disiplin ilmu yang terpisah melainkan mengacu pada aspek kehidupan nyata (factual/real) peserta didik (Sapriya, 2008 : 160). Secara konseptual, materi pelajaran ips di SD belum mencakup dan mengakomodasi seluruh disiplin ilmu social. Namun, ada ketentuan bahwa melalui mata pelajaran ips, peserta didik diarahkan untuk dapat menjadi warga negara indonesia yang demokratis dan beratanggung jawab serta warga dunia yang cinta damai. Salah satu materi IPS yang menunjang siswa menjadi pribadi yang lebih baik dan mencintai negaranya adalah sikap kepahlawanan dan patriotisme. Materi ini diberikan kepada siswa kelas IV dengan tujuan siswa dapat mengamalkannya dalam kehidupan sehari-hari.

Penelitian tindakan kelas yang diajukan ini mempunyai judul "Penerapan Metode Pembelajaran Card Sort Dalam Upaya Peningkatan Hasil Belajar Pokok Bahasan Sikap Kepahlawanan Dan Patriotism Kelas IV SDN Purwosari 02"

Belajar secara sederhana dapat diartikan sebagai suatu tindakan atau perbuatan yang secara sadar dilakukan oleh seseorang untuk mengumpulkan berbagai bentuk informasi baik dilakukan di dalam kelas maupun di luar kelas. Model pembelajaran adalah pola yang digunakan guru sebagai pedoman untuk merencanakan pembelajaran di kelas. Menurut Arends, model pembelajaran mengacu pada pendekatan yang akan digunakan, termasuk di dalamnya tujuantujuan pembelajaran, tahap-tahap dalam kegiatan pembelajaran, lingkungan pembelajaran, dan pengelolaan kelas. Berdasarkan pernyataan tersebut, model pembelajaran dapat kita definisikan sebagai kerangka konseptual yang menggambarkan prosedur sistematis dalam mengorganisasikan pengalaman belajar untuk mencapai tujuan pembelajaran.

Menurut Melvia L. Silberman, model Card Sort merupakan kegiatan 
kolaboratif yang bisa digunakan untuk mengerjakan konsep, penggolongan sifat, fakta tentang suatu objek atau mengulangi informasi. Strategi ini juga menekankan pada gerakan fisik yang diutamakan dapat membantu memberikan energi kepada suasana kelas yang mulai jenuh, karena aktifitas pembelajaran yang sangat padat.

Model pembelajaran card sort yang dapat kita artikan sebagai "sortir kartu"merupakan salah satu bentuk pembelajaran kolaboratif yang dapat diterapkan untuk mengajarkan konsep penggolongan, sifat, serta fakta tentang suatu obyek, atau mengulang informasi yang telah dipelajari sebelumnya. Dalam pembelajaran model card sort, gerakan fisik yang dilakukan siswa dapat membantu memberi energi pada kelas yang telah letih. Model pembelajaran ini dapat mengajak siswa untuk belajar aktif . tujuan pembelajaran adalah agar siswa mempunyai jiwa kemandirian dalam belajar dan menumbuhkan daya kreativitas. Model pembelajaran card sort atau menyortir kartu ini adalah model pembelajaran yang cukup sederhana. Media pembelajaran yang digunakan yang terdiri dari kartu induk dan kartu rincian yang berisikan materi yang akan disampaikan pendidik kepada siswa/ peserta didik.

Pengertian Penelitian Tindakan Kelas (PTK) berkembang dari istilah penelitian tindakan (action research) (Sanjaya, 2006 : 24). Oleh karena itu, untuk memahami pengertian PTK perlu ditelusuri pengertian penelitian tindakan terlebih dahulu. Penelitian tindakan mulai berkembang di Amerika dan berbagai negara di Eropa, khususnya dikembangkan oleh mereka yang bergerak di bidang ilmu sosial dan humaniora (Basrowi \& Suwandi, 2008 : 24-25).

\section{METODE PENELITIAN}

Penelitian ini merupakan jenis

Penelitian Tindakan Kelas (PTK)

merupakan penelitian tindakan yang dilakukan dengan tujuan untuk memperbaiki praktik pembelajaran di kelas. Subyek dari penelitian ini adalah siswa siswi kelas IV di SDN Purwosari 02 yang berjumlah 34 siswa. Waktu penelitan dilaksanakan bulan Januari 2016 dengan durasi 2 kali pertemuan selama $2 \times 35$ menit. Penelitian ini dilaksanakan dalam dua siklus. Sesuai dengan materi IPS yang telah dibahas, maka ditemukan sebuah fenomena bahwa siswa terkesan tidak terlalu menyukai pembelajaran IPS dikarenakan hanya menggunakan metode ceramah yang dilakukan oleh guru. Sehingga siswa terlihat bosan dengan pembelajaran indikasi kebosanan itu dapat terlihat dari pasifnya siswa dalam mengikuti pembelajaran atau kurang aktif ketika dijelaskan tentang materi dan ketika pemberian tugas. Ini tentu berakibat pada nilai ulangan harian IPS yang cenderung rendah dan banyak yang tidak mencapai KKM. Maka untuk mengatasi masalah tersebut diperlukan suatu metode yang dapat membuat siswa aktif, dapat menemukan konsep sendiri dan meningkatkan hasil belajar siswa. Metode yang diharapkan dapat mengatasi masalah pembelajaran dari siswa yang tidak aktif, kesulitan siswa menemukan konsep pembelajaran dan kurangnya rata-rata hasil belajar siswa adalah metode pembelajaran card sort .

\section{HASIL DAN PEMBAHASAN}

Sesuai dengan materi IPS yang telah dibahas maka ditemukan fakta di lapangan di SDN Randuagung 01 siswa mengalami kesulitan dalam pemahaman konsep sistem pemerintahan. Hal itu disebabkan belum adanya metode pembelajaran yang membuat siswa menemukan konsep dengan sendirinya. Siswa cenderung pasif dalam pembelajaran, ditandai dengan tidak ada siswa yang membaca materi sebelum pelajaran dimulai. Siswa aktif hanya saat ada tugas saja. Halitu berdampak pada ulangan harian materi PKn sebelumnya yang mendapatkan rata-rata nilai 75 dengan nilai minimal KKM. Maka untuk 
mengatasi masalah tersebut diperlukan suatu metode yang dapat membuat siswa aktif, dapat menemukan konsep sendiri dan meningkatkan hasil belajar siswa.

Hasil tes formatif siswa yang mencapai KKM dengan rata-rata 60 . Kemudian kegiatan siklus I dilanjutkan dengan menyusun kegiatan revisi I untuk perbaikan pada siklus selanjutnya. Pada tes formatif yang dilaksanakan pada siklus I jumlah siswa yang mencapai KKM 75 adalah sejumlah 8 siswa dengan prosentase $23.5 \%$ saja, sedangkan yang belum mencapai adalah mayoritas siswa dengan jumlah 26 siswa yang belum mencapai KKM dengan prosentase $23.5 \%$. Berikut adalah hasil tes formatif siswa kelas IV SDN Purwosari 02 adalah .

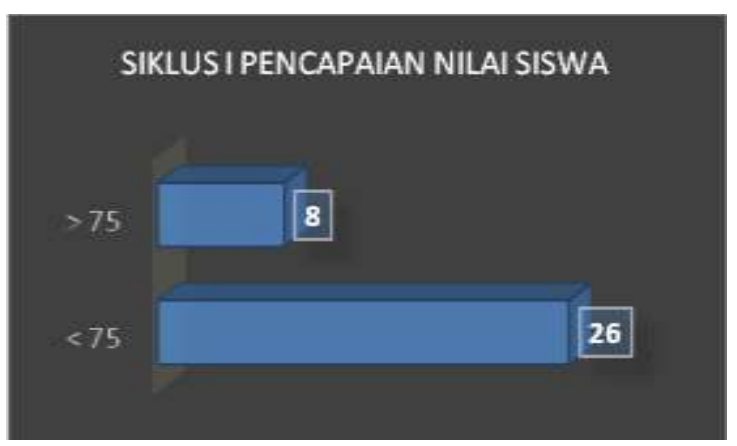

Gambar 1. Grafik Rekapitulasi Hasil Tes Formatif Siswa Siklus

Pada siklus II, diawali dengan menyusun kegiatan revisi I untuk perbaikan pada dari siklus I. Kegiatan siklus II merupakan implementasi dari kegiatan revisi I yang disusun di akhir kegiatan siklus I.

Kegiatannya adalah kegiatan perbaikan langkah-langkah pembelajaran agar sesuai dengan skenario pembelajaran yang disusun. penjelasan yang diberikan guru berfokus pada cara kerja siswa dalam mencari pasagan kartu, agar memperhatikan instruksi/topik yang disediakan. Kemudian, siswa bekerja berkelompok dengan menata kartu serta mempresentasikan di depan kelas secara bergantian. Siklus 2 ditutup dengan postes 2 dan rangkuman oleh guru dan siswa tentang hal-hal yang telah dipelajari.
Sementara siklus 1 dan 2 berlangsung, kolaborator melakukan observasi dengan menggunakan lembar observasi yang telah tersedia. Hasil observasi berupa data tentang proses belajar, situasi kelas, dan masalah yang dihadapi siswa (secara otentik berdasarkan nama siswa). Setelah kegiatan belajar berakhir, guru menuliskan refleksi dari pelaksanaan kegiatan belajar mengajar yang dilakukannya. Pengumpulan data dan analisis data Data dikumpulkan dari hasil observasi rekan guru dengan menggunakan lembar observasi yang tersedia, dan dari tes hasil belajar (pretes dan postes) pada saat pelaksanaan tindakan selama 2 siklus, serta refleksi diri yang dilakukan guru terhadap kegiatan belajar mengajar yang telah dilaksanakan sebanyak 2 siklus. Pada kegiatan siklus II ini peneliti sudah melaksanakan kegiatan revisi I dan langkah-langkah metode sudah ada perbaikan. Hasil tes formatif siswa sudah menunjukkan peningkatan yang signifikan dengan rata-rata nilai kelas adalah 79. Rincian adalah sebagai berikut siswa yang belum mencapai KKM sejumlah 6 siswa dengan prosentase $17.6 \%$, sedangkan siswa yang mencapai nilai KKM sejumlah 28 siswa dengan prosentase $82.4 \%$. Berikut grafik siswa hasil tes formatif siswa kelas IV:

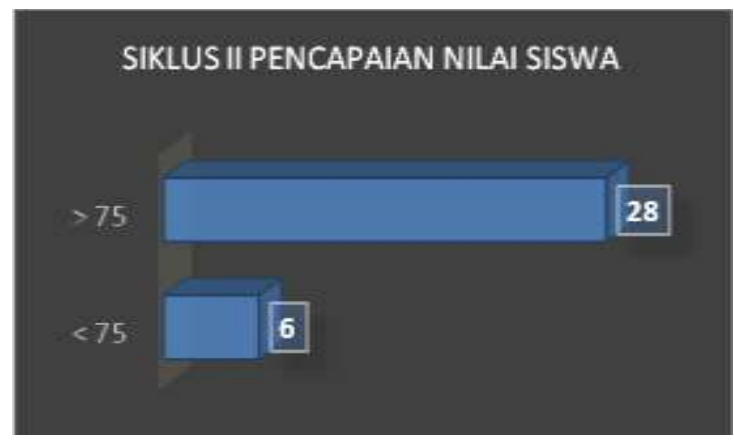

Gambar 2. Grafik Rekapitulasi Hasil Tes Formatif Siswa Siklus II

Dari hasil pelaksanaan siklus 1 dan siklus 2, yang telah dikemukakan diatas, pada pelaksanaan tindakan dapat diketahui perubahan-perubahan baik dari cara belajar siswa dan hasil belajarnya dengan 
diadakannya pembelajaran menggunakan metode card sort dengan pembahasan sebagai berikut: Interaksi siswa dalam kegiatan belajar mengajar dengan metode card sort pada permulan siklus I: Pada saat pembentukan kelompok siswa tidak segera melaksanakan tugas tapi malah membuat kegaduhan, mondar-mandir, mengobrol, sehingga menyita waktu 10 menit. Selama pelaksanaan kegiatan belajar mengajar kegaduhan kelas mulai berkurang, kekurangan lainnya adalah, aktivitas siswa tidak merata, kerjasama kelompok sebagaian ada yang belum kompak, masih ada siswa yang pasif dan masa bodoh. Keadaan tersebut menjadi bahan catatan dan direncanakan melalui kegiatan refleksi, sehingga diperlukan perencanaan pembelajaran agar diperbaiki pada siklus 2 menjadi lebih baik, dan hal ini bisa di lihat dari hasil siklus 2 dengan kondisi sebagai berikut: Pada saat pembentukan kelompok, siswa segera melaksanakan tugas, sudah tidak ditemukan lagi siswa yang mondar-mandir ataupun mengobrol. kelompok segera terbentuk dan sesuai dengan rencana. Selama pelaksanaan kegiatan belajar mengajar kegaduhan kelas mulai berkurang, dan siswa terlihat aktif dalam mengikuti kegiatan belajar mengajar, kerjasama kelompok mulai terlihat hidup dengan masing- masing siswa memberikan usulan untuk menemukan jawaban. Metode pembelajaran card sort merupakan salah satu solusi yang cukup baik ditawarkan pada proses pembelajaran IPS. Dengan adanya pembuatan card sort bagi setiap siswa memudahkan siswa dalam memahami konsep IPS dengan baik. Hasil belajar siswa juga meningkat dibandingkan rata-rata ulangan harian siswa sebelum mendapatkan metode pembelajaran card sort.

\section{PENUTUP}

Berdasarkan hasil penelitian dan pembahasan yang telah dipaparkan oleh peneliti, maka dapat disimpulkan bahwa:
1. Metode pembelajaran card sort mapping dapat meningkatkan hasil belajar siswa.

2. Dengan metode pembelajaran card sort membuat siswa menjadi lebih kreatif dalam menjabarkan konsep materi IPS.

Oleh sebab itu dengan penerapan metode pembelajaran card sort dapat dikembangkan untuk meningkatkan proses pembelajaran di kelas dan hasil belajar siswa.

\section{DAFTAR PUSTAKA}

Fatah Yasin, 2008, Dimensi-Dimensi

Pendidikan Islam, Malang: UIN

Malang Press Arifin. 2010.

Penelitian Pendidikan :

Pendekatan Kuantitatif dan

Kualitatif. Lilin Persada Press.

Basrowi \& Suwandi. 2008. Memahami

Penelitian Kualitatif. Jakarta :

Rineka Cipta.

Departemen Pendidikan Nasional, 2003.

Undang-Undang Nomor 20 Tahun

2003, Tentang Sistem Pendidikan

Nasional, Jakarta: Depdiknas.

Depdiknas. (2006). Kurikulum Tingkat

Satuan Pendidikan (KTSP).

Jakarta:Departemen Pendidikan

Nasional.

H. Daryanto. (2005). Evaluasi pendidikan.

Jakarta : Rineka Cipta. Jarolimek,

John. 1993. Social studies in

Elementary Education $\left(9^{\text {th }} \cdot\right.$ Ed $)$.

New York: Macmilan

Publishing.co.Ltd).

Kunandar. 2012. Langkah Mudah

Penelitian Tindakan Kelas Sebagai

Pengembangan Profesi Guru.

Jakarta : Rajawali Pers.

Muhammad Asrori, 2012. Penelitian

Tindakan Kelas. Bandung: CV Wacana Prima

Mulyasa, 2004. Implementasi Kurikulum Tingkat Satuan Pendidikan Kemandirian Guru dan Kepala Sekolah. Bandung: PT Remaja Rosdakarya. 
Sapriya, dkk. 2008. Konsep Dasar IPS.

Bandung: Laboratorium PKN

Universitas Pendidikan Indonesia.

Sapriya, dkk. 2008. Pendidikan IPS.

Bandung: Laboratorium PKN.

Universitas Pendidikan Indonesia.

Sanjaya, Wina. 2006. Strategi

Pembelajaran. Jakarta : Kencana

Prenada Media Group.

Sumarno, 2003. Pendidikan

Kewarnegaraan. Jakarta: PT

Pustaka Tiga Kelana Sumiati \& Asra. (2009). Metode Pembelajaran.

Bandung: CV Wacana Prima.

Winaputra, US. 2008. Materi dan

Pembelajaran $P K n$ SD. Jakarta:

Universitas Terbuka 